\title{
Templating Conducting Polymers via Self-assembly of Block Copolymers and Supramolecular Recognition
}

\author{
Lynne A. McCullough, Bruno Dufour, Chuanbing Tang ${ }^{\S}$, Rui Zhang, Tomasz \\ Kowalewski, Krzysztof Matyjaszewski* \\ Carnegie Mellon University, Department of Chemistry, Pittsburgh, PA 15232 \\ ${ }^{\S}$ Current address: Materials Research Laboratory, University of California, Santa \\ Barbara, California 93106
}

\section{Supporting Information}

Experimental: The aniline, AMPSA, methyl acrylate, methanol, sodium methoxide, benzyl chloride, $\alpha$-methyl styrene, carbon tetrachloride, sulfur, and dichloroacetic acid were all purchased from Aldrich. Aniline was distilled under vacuum before use, while the methyl acrylate was passed through a basic alumna column to remove the radical inhibitor.

Analysis: Monomer conversions were determined by gas chromatography (GC) with a Shimadzu GC-14A gas chromatograph equipped with a flame ionization detector, and using a capillary column (CEC-Wax, $30 \mathrm{~m} \times 0.53 \mathrm{~mm} \times 1.0 \mu \mathrm{m}$, Chrom Expert Co.). The NMR spectra (in $\mathrm{D}_{2} \mathrm{O}$ or DMSO- $\mathrm{d}_{6}$ with tetramethylsilane as the reference) were recorded on a Bruker instrument operating at $300 \mathrm{MHz}$. Template molecular weights were determined by size exclusion chromatography (SEC) using $50 \mathrm{mM}$ solution of $\mathrm{LiBr}$ in DMF (flow rate $1 \mathrm{~mL} / \mathrm{min}, 50{ }^{\circ} \mathrm{C}$ ) with a series of three Styragel columns $\left(10^{5} \AA, 10^{3}\right.$ 
$\AA, 100 \AA$; Polymer Standard Services) and a Waters 2410 differential refractometer as the detector. Calibration based on polystyrene standards was used with toluene as the elution volume marker. The polymer solutions were filtered through neutral alumina columns attached to a $0.2 \mu \mathrm{m}$ PTFE filter prior to the analysis.

Tapping mode atomic force microscopy (TMAFM) studies were carried out with the aid of a NanoScope III-M system (Veeco Corp., Santa Barbara, CA), equipped with a J-type vertical engage scanner. The AFM observations were performed at room temperature under air using silicon cantilevers with nominal spring constant of $40 \mathrm{~N} / \mathrm{m}$ and nominal resonance frequency of $300 \mathrm{kHz}$ (standard silicon TESP probes). Typically, the cantilever was oscillated at the frequency at which the oscillation amplitude was equal to $10-20 \%$ of amplitude on resonance.

Electrical conductivity measurements were conducted on free-standing polymer films by the standard spring-loaded pressure-contact four-point probe method in ambient conditions. Six repeated measurements were taken from $1 \mathrm{~cm}$. x $1 \mathrm{~cm}$. samples of uniform area. The conductivity $\sigma(\mathrm{S} / \mathrm{cm})$ was calculated according to the following equation:

$$
\sigma=1 \div 4.53 \times R \times l
$$

where $R$ is the resistance $(R=V / I)[\mathbf{\Omega}]$ and $l$ is the film thickness $(\mathrm{cm})$.

Transmission Small Angle X-ray Scattering: Transmission SAXS images of sample polyaniline samples were taken at Cornell High Energy Synchrotron Source (CHESS) D1 station. A wide bandpass (1.47\%) double-bounce multilayer monochromator supplied an intense beam of $10.1 \mathrm{keV}$ photons which impinged onto thick sample thin film. 
Transmission SAXS scattering intensities were recorded with an area detector (Medoptics) with a resolution of $47.19 \mu \mathrm{m}$ per pixel and a total area of about $50 \mathrm{~mm}$ by $50 \mathrm{~mm}$ at a distance of $1210 \mathrm{~mm}$ from the sample. The intense scattering was blocked with a $1.5 \mathrm{~mm}$ wide tantalum rod. Exposures times under these conditions ranged from $10 \mathrm{sec}$ to $30 \mathrm{sec}$ depending on contrast and sample quality.

Transmission SAXS images of oligoaniline samples were recorded with Molecular Metrology SAXS consisting of a standard three-pinhole camera (Molecular Metrology) with a Bede microfocus $\mathrm{Cu}-\mathrm{K}_{\boldsymbol{c e}} \mathrm{X}$-ray source $(\lambda=1.54 \AA)$ and Osmic MaxFlux graded multilayer optics. The patterns are collected on a $12.5 \mathrm{~cm}$ diameter 2D multiwire gasfilled detector. The detector was calibrated using silver behenate standard. Exposure times under these conditions were 1 hour.

\section{Synthesis of cumyl dithiobenzoate:}

Dithiobenzoic acid

A 3-necked $1 \mathrm{~L}$ round bottom flask was dried overnight and fitted with a magnetic stir bar, a dried $250 \mathrm{~mL}$ addition funnel, a dried condenser, and a septum. Sodium methoxide ( $30 \%$ by weight in methanol) was added $(188 \mathrm{~mL})$. Anhydrous methanol (316 $\mathrm{mL}$ ) was added by syringe, quickly followed by sulfur (32.04 g). This mixture was stirred, and then $57 \mathrm{~mL}$ of benzyl chloride were added by addition funnel, over 1.5 hours. The mixture was then heated to $67^{\circ} \mathrm{C}$ overnight in an oil bath. The next morning the reaction was cooled in an ice bath, then filtered by vacuum. The methanol was removed by rotary evaporation, and then $500 \mathrm{~mL}$ of water were added, and the mixture was filtered a second time. The liquid was then split into two portions, and washed with 
$3 \times 150 \mathrm{~mL}$ ether. The ether layers were discarded, and $100 \mathrm{~mL}$ ether and $250 \mathrm{~mL} 1 \mathrm{~N} \mathrm{HCl}$ were used to wash the water layer. The ether layer was then washed with $200 \mathrm{~mL} 1 \mathrm{~N}$ $\mathrm{NaOH}$. The washing process was repeated one more time, and finally the dithiobenzoic acid was extracted into carbon tetrachloride.

\section{Cumyl dithiobenzoate}

Dithiobenzoic acid was previously prepared and was extracted directly into carbon tetrachloride. $\alpha$-Methyl styrene ( $10.4 \mathrm{~g}, 1.25 \mathrm{~mol} \%$ excess) was added to dithiobenzoic acid $(11.09 \mathrm{~g})$ in carbon tetrachloride $(40 \mathrm{~mL})$ (Scheme 1). The resulting solution was purged with nitrogen to help prevent the degradation reactions of the dithiobenzoic acid that are known to occur upon exposure to air. The reaction was conducted with constant stirring at $70^{\circ} \mathrm{C}$ for $5 \mathrm{~h}$. The crude product was obtained as a dark violet oil in $69 \%$ yield and was subsequently purified by column chromatography (neutral alumina packing, $n$-hexanes as eluent). After purification ${ }^{1} \mathrm{H}$-NMR spectroscopy (in $\mathrm{CDCl}_{3}$ ) confirmed the presence of only one compound.

Polyaniline (PANI): Aniline (30 mL), $\mathrm{LiCl}$ (48 g), ethanol (285 mL), and $\mathrm{HCl}$ (3M, 355 $\mathrm{mL}$ ) were mixed together and cooled to $-15^{\circ} \mathrm{C}$ with stirring. After 3 hours, ammonium persulfate $(18.75 \mathrm{~g}), \mathrm{LiCl}(24 \mathrm{~g})$, and $\mathrm{HCl}(2 \mathrm{M}, 180 \mathrm{~mL})$ were mixed together and added to the initial solution, and this mixture was stirred for 16 hours. The reaction temperature was then raised to $5^{\circ} \mathrm{C}$ and the mixture was allowed to equilibrate. The polyaniline was collected and filtered by vacuum, then washed with $1 \mathrm{~L} \mathrm{HCl}(3 \mathrm{M}), 2 \mathrm{~L}$ of water, stirred for 2 days in $2 \mathrm{~L} \mathrm{NH}_{4} \mathrm{OH}(0.1 \mathrm{M})$, washed with methanol until the liquid was no longer a dark purple, and washed with $200 \mathrm{~mL}$ ether to remove the methanol. The powder was 
then transferred to a jar, and dried in the vacuum oven (no heat) until it reached a consistent mass.

\section{Synthesis of poly (acrylamido-2-methyl-N-propanesulfonic acid) by RAFT: AMPSA}

(10 g), degassed methanol $(40 \mathrm{~mL})$, and cumyl dithiobenzoate $(71 \mathrm{mg})$ were added to a degassed Schlenk flask. After several hours of stirring to solubilize the monomer, azoisobutyronitrile $(8.1 \mathrm{mg}$ ) was added, degassed, and then the flask was lowered into the oil bath $\left(60^{\circ} \mathrm{C}\right)$. The reaction was stopped when the mixture turned from cloudy to clear $(60 \%$ conversion by NMR). The solvent was removed by rotary evaporation and the remaining polymer was dissolved in $30 \mathrm{~mL}$ water for purification by dialysis. The water was then removed by vacuum. ${ }^{1} \mathrm{H}-\mathrm{NMR}$ was used to determine the molecular weight of the polymer $(14,500 \mathrm{~g} / \mathrm{mol}$, DP 70$)$, and water GPC was used to obtain the polydispersity (1.36).

PAMPSA block extension with methyl acrylate: PAMPSA $(0.8065 \mathrm{~g})$ was added to a Schlenk flask and degassed for 30 minutes. Degassed methanol (6 mL), methyl acrylate (4 mL), anisole $(1 \mathrm{~mL})$ and AIBN $(1.1 \mathrm{mg})$ were then added, and the flask was heated to $60^{\circ}$ in an oil bath. The reaction was monitored by GC, and the final composition was determined by elemental analysis.

Preparation of PANI/block copolymer complex: A 1\% solution (by weight) of PANI/AMPSA 2 in dichloroacetic acid was prepared by mixing PANI ( $1 \mathrm{~g})$, AMPSA $(1.144 \mathrm{~g})$, and dichloroacetic acid $(100 \mathrm{~g})$ in a flask. When the mixture turned a uniform 
dark green, the polyaniline was both doped and solubilized, and could be used to prepare the PANI /block copolymer complexes. A 5\% solution (by weight) of the block copolymer was also prepared in dichloroacetic acid. Portions of the PANI solution were pipeted into the block copolymer solution, and the mixtures were stirred in order to facilitate formation of the complexes. The existence of doping was determined by identification of the polaron delocalization band above $600 \mathrm{~nm}$ in UV-Vis spectra.

Film preparation: A clean Petri dish was lined with polyethylene film, fastened in place by double-sided tape. The polyaniline/block copolymer complex was dropped onto the central flat portion, and dried in a vacuum oven for $24-36$ hours at $\sim 70^{\circ} \mathrm{C}$. 


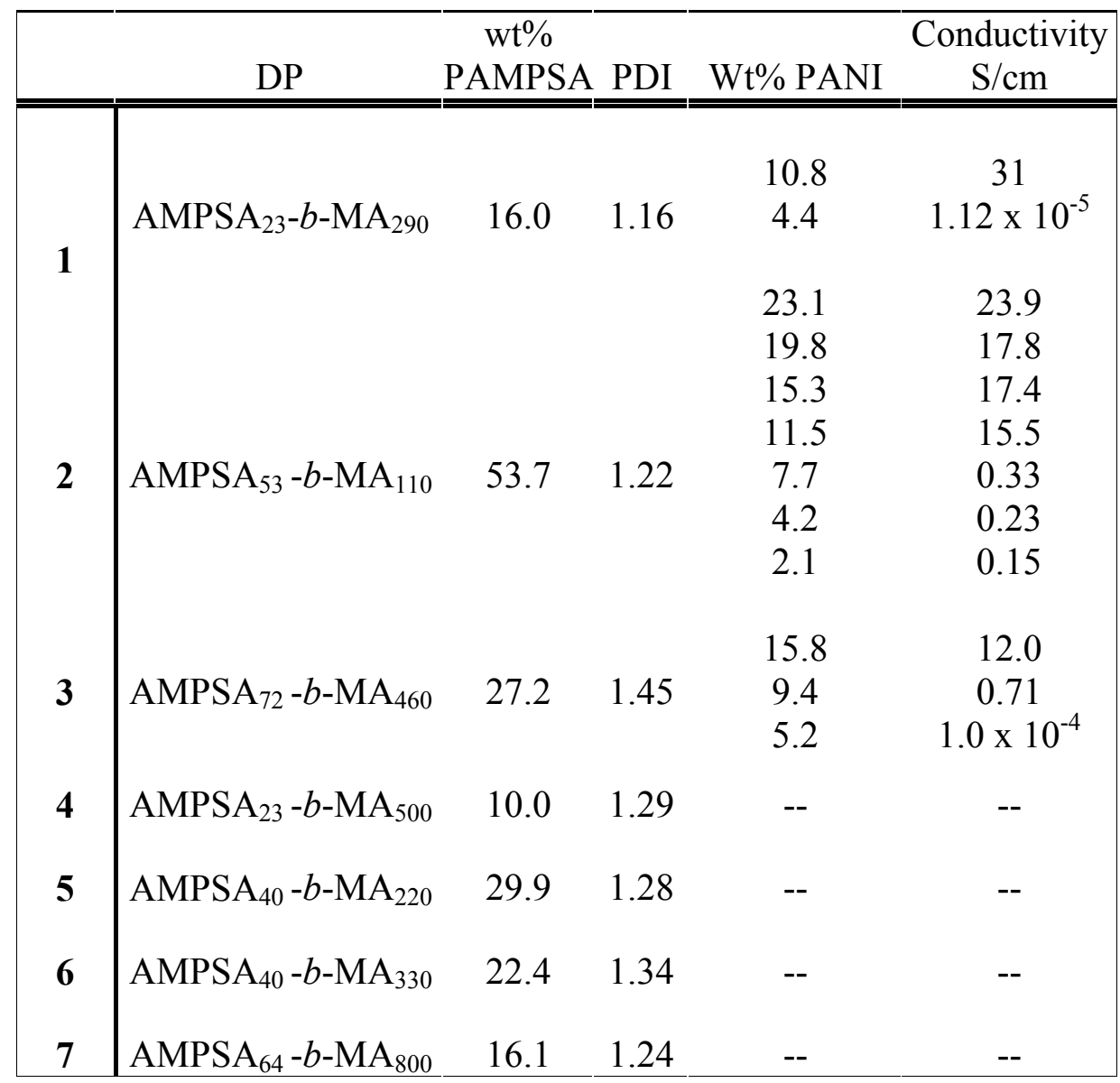

Table S1. Data on the preparation of block copolymers by RAFT and the complexes formed after addition of the conducting PANI. 


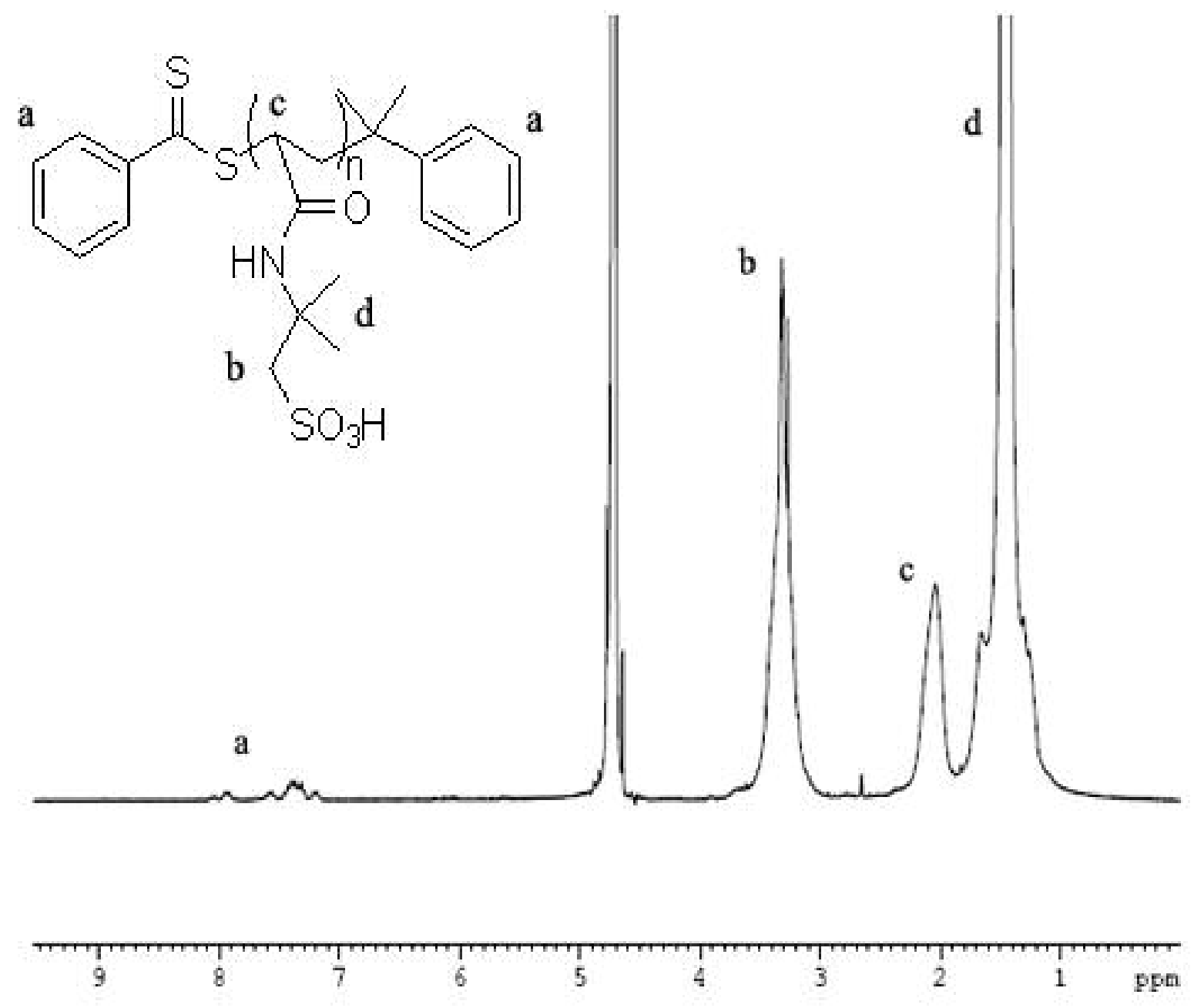

Figure S1. ${ }^{1}$ H-NMR of PAMPSA prepared via RAFT with cumyl dithiobenzoate as the RAFT agent. 


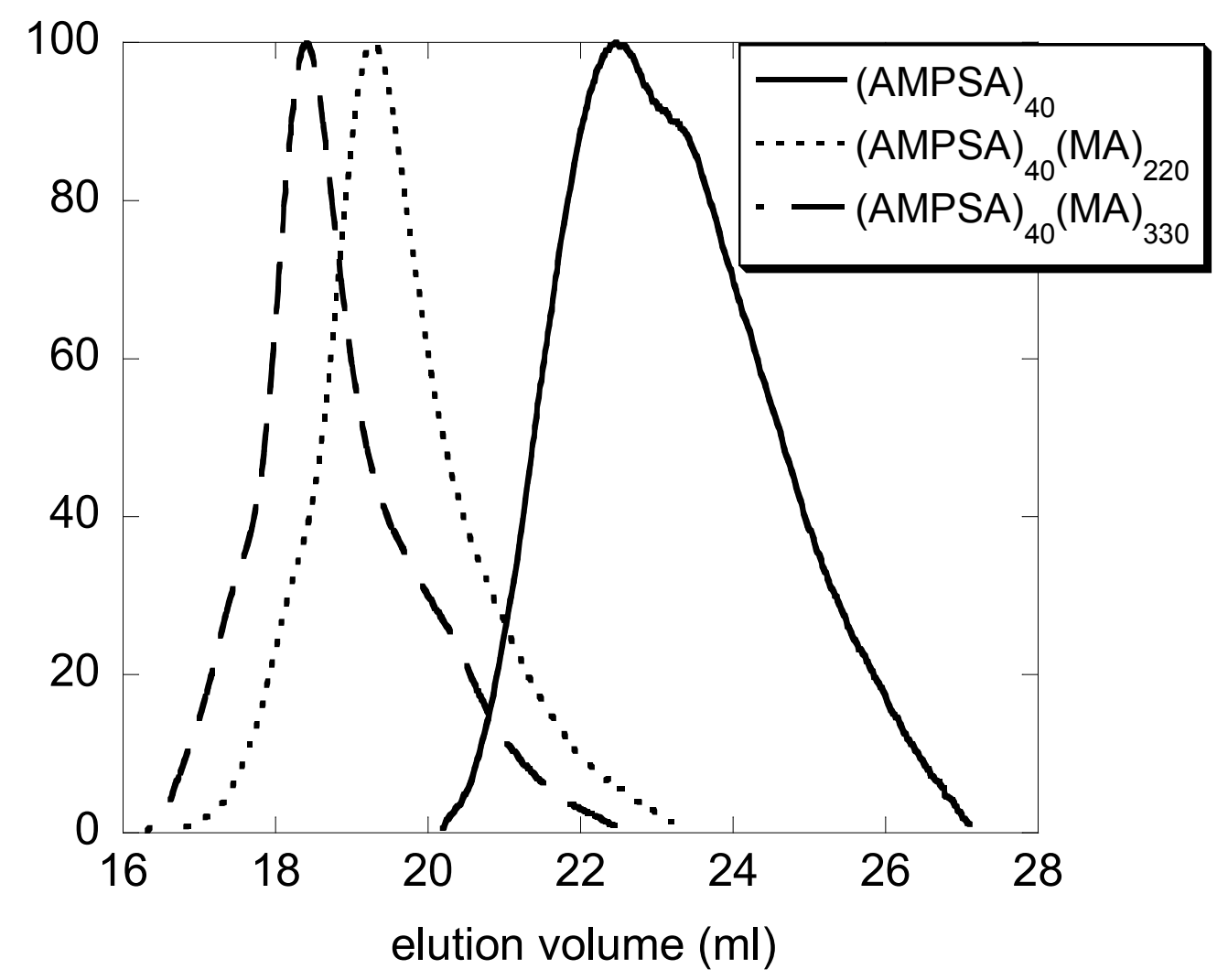

Figure S2. GPC traces (in DMF) of PAMPSA macroinitiator and block copolymers with methyl acrylate as prepared by RAFT. 

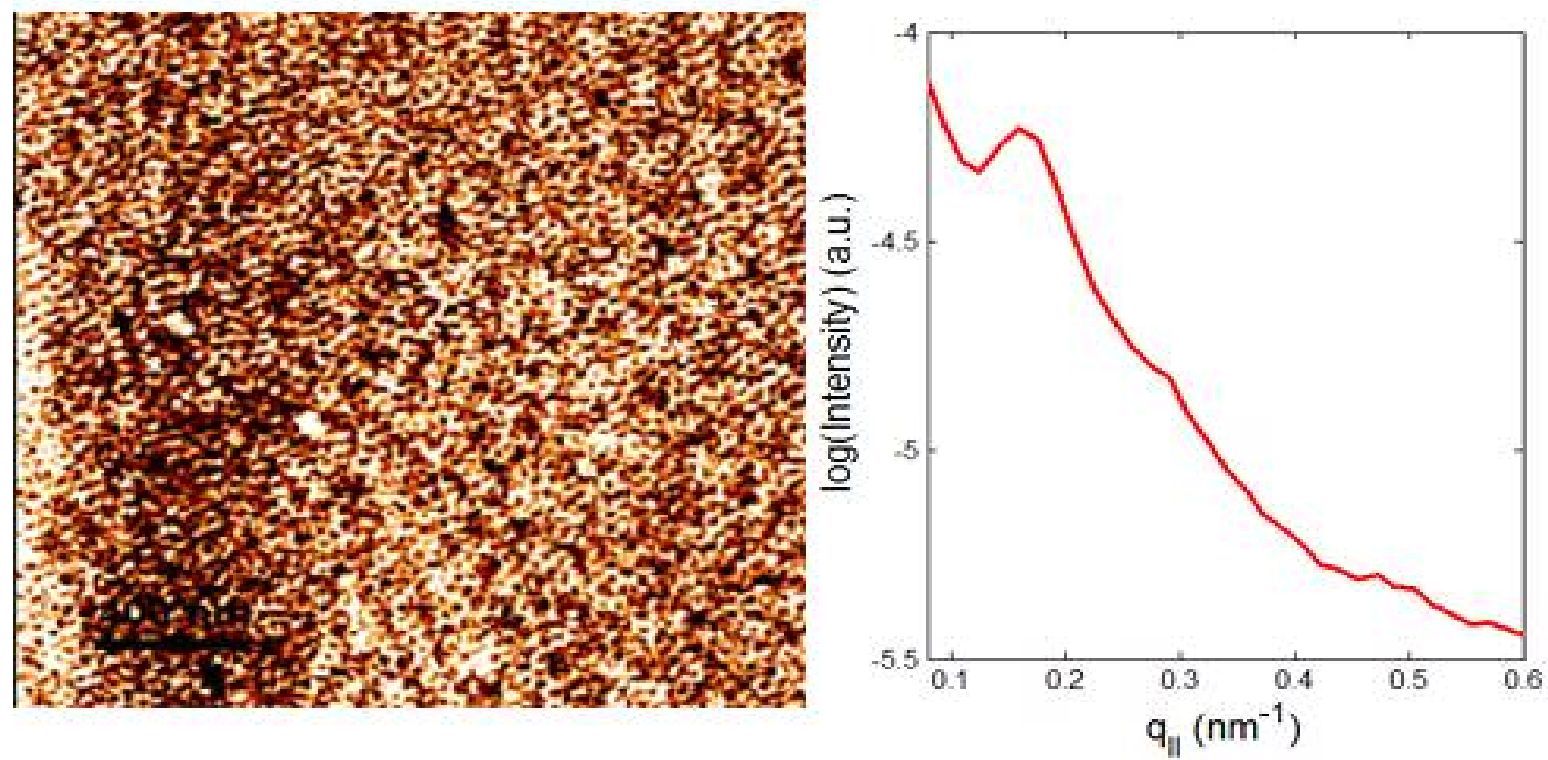

Figure S4. AFM (left) and SAXS (right) of $4 \mathrm{~EB}_{2.3} /(\mathrm{AMPSA})_{23}(\mathrm{MA})_{500}$ $(d=32.3 \mathrm{~nm})$ 

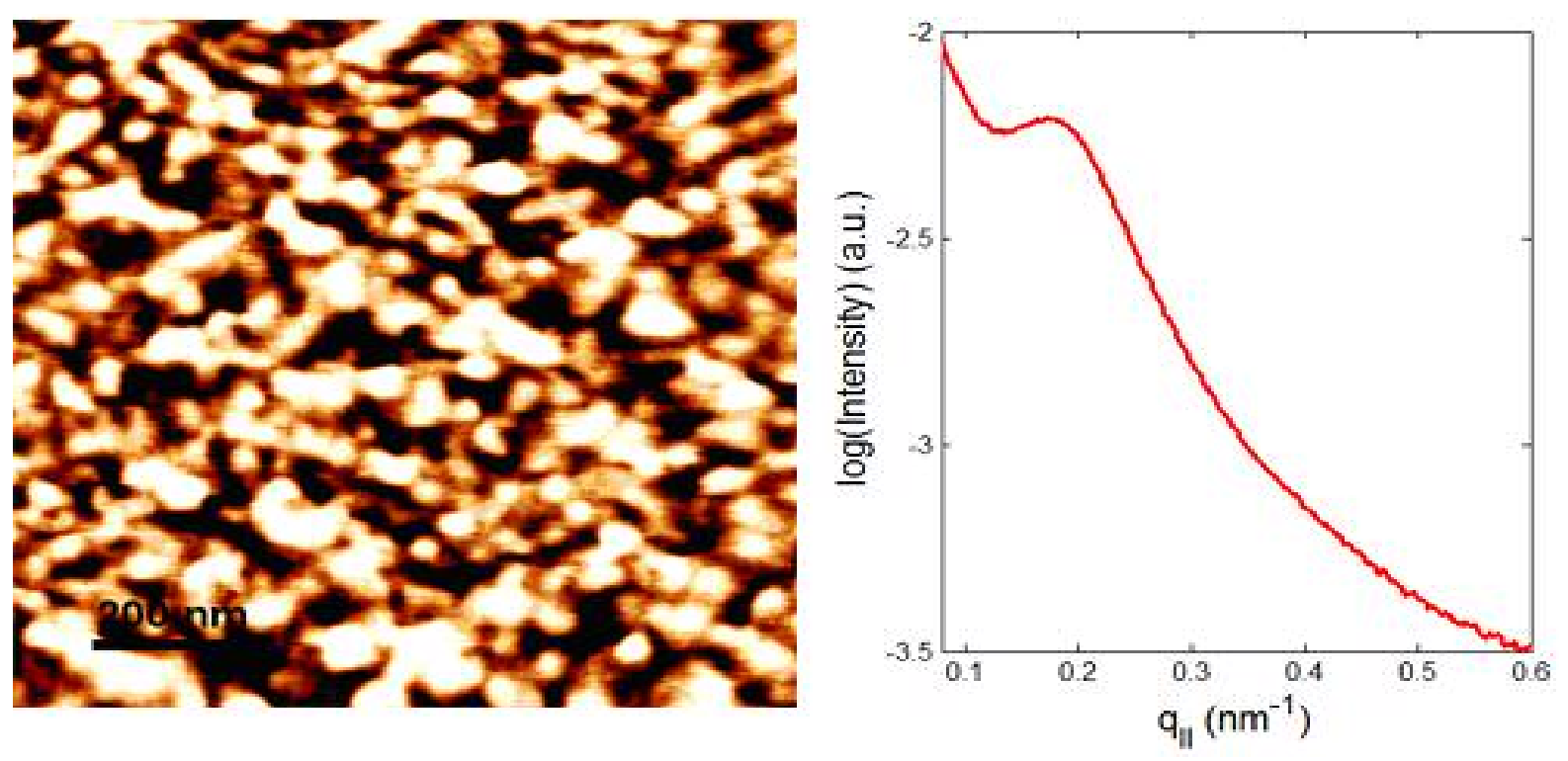

Figure S5. AFM (left) and SAXS (right) of (Pani(AMPSA) $\left.)_{1,4}\right)_{11.5} /(\text { AMPSA })_{23}(\mathrm{MA})_{290}$ $(d=35.8 \mathrm{~nm})$ 

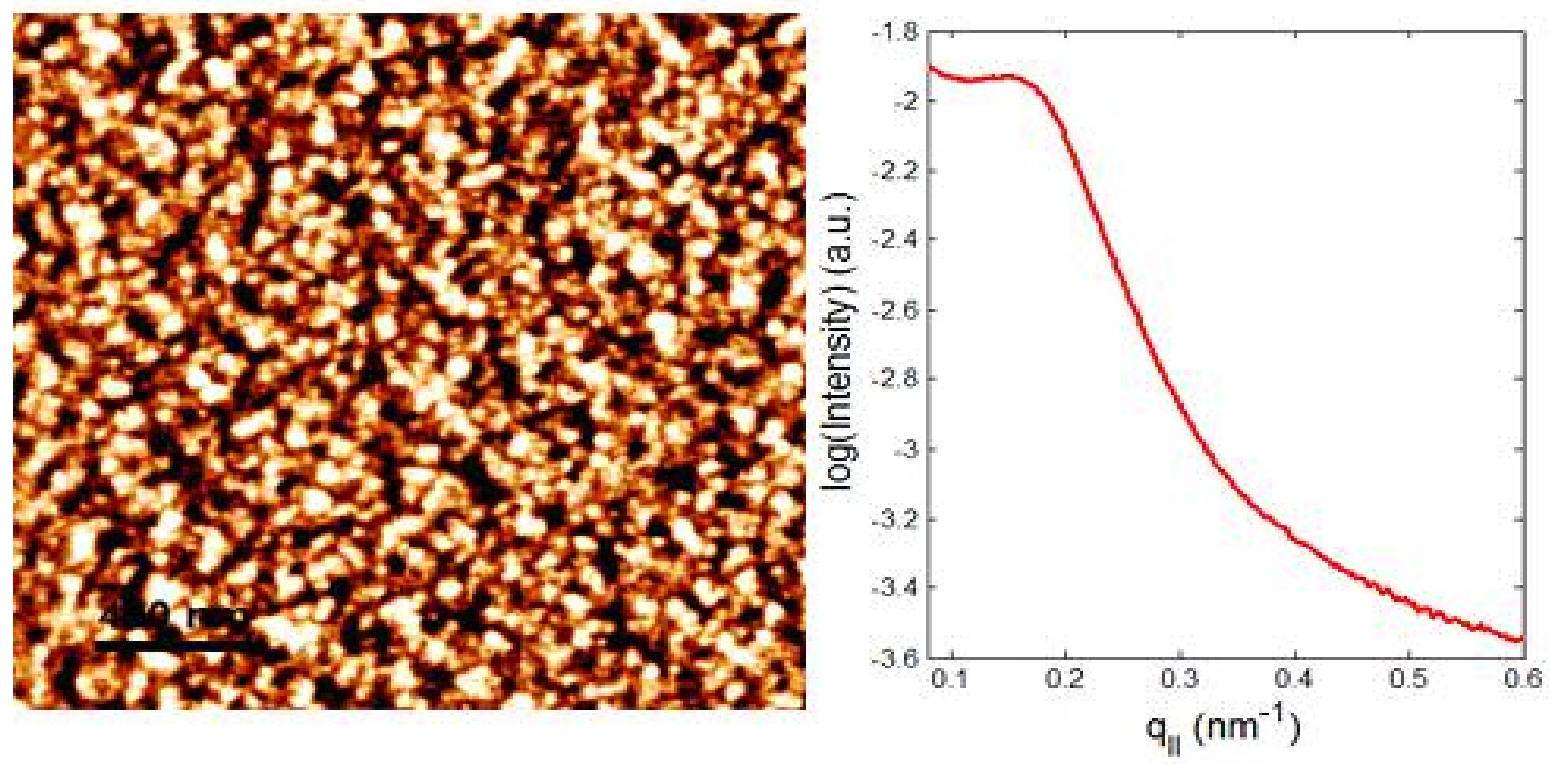

Figure S6. AFM (left) and SAXS (right) of (Pani(AMPSA) $\left.)_{2}\right)_{11.5} /(\text { AMPSA })_{23}(\mathrm{MA})_{290}$ $(d=41.5 \mathrm{~nm})$ 